\title{
As Atitudes dos Agricultores Face à Política Agrícola Comum e ao Projecto de Regadio de Alqueva ${ }^{1}$
}

\author{
Maria José Palma Lampreia dos Santos² \\ Pedro Damião de Sousa Henriques ${ }^{3}$ \\ Rui Manuel de Sousa Fragoso ${ }^{4}$ \\ Maria Leonor Silva Carvalho ${ }^{5}$
}

Resumo: O principal objectivo deste artigo é conhecer as atitudes dos agricultores face à produção agrícola, ao apoio político e ao projecto de rega de Alqueva numa micro-região mediterrânica do Sul de Portugal, no contexto da Política Agrícola Comum (PAC) de 2003 e do Health-Check. Simultaneamente, pretende-se conhecer as intenções comportamentais destes agricultores frente à inovação tecnológica e ao futuro regadio público neste contexto político. Os resultados destacam que a grande maioria destes agricultores constituem um grupo relativamente homogéneo face às suas atitudes. Este cluster mantém uma mentalidade muito produtivista, um forte desejo de manter um foco agrícola, rejeitando veementemente noções de liberalização política. Apesar de possuírem elevada capacidade inovadora e de estarem conscientes da importância do seu contributo na defesa do mundo rural, reconhecem que as futuras condições institucionais da PAC, do fornecimento da água do regadio de Alqueva e das condições de acesso ao crédito, lhes poderá comprometer os seus planos inovadores no futuro. Por isso, conclui-se que é necessário compreender as especificidades da agricultura regional nos diversos países da União Europeia para que as políticas tenham êxito local. No caso português, são necessários estudos mais abrangentes de forma a encontrar resultados mais consistentes.

1 Trata-se de um artigo cujo autores são de Portugal. Dessa forma, o artigo está escrito em português corrente utilizado em Portugal, em que não há correspondência de termos com o português utilizado no Brasil, mesmo para textos científicos em economia.

2 Professora Auxiliar, Universidade Lusófona do Porto - Centro de Estudos Naturais, Ambiente e Sociedade - CERNAS, Bencanta, 3040-316 Coimbra Portugal. Email: mjpls1963@gmail.com

3 Professor Associado, Departamento de Economia, Universidade de Évora, CEFAGE, Largo dos Colegiais, 7000 Évora, Portugal. Email: pdamiao@uevora.pt

4 Professor Auxiliar, Departamento de Gestão, Universidade de Évora, CEFAGE, ICAAM, Largo dos Colegiais, 7000 Évora, Portugal.Email: rfragoso@uevora.pt

5 Professora Associada, Departamento de Economia, Universidade de Évora, ICAAM, CEFAGE, Largo dos Colegiais, 7000 Évora, Portugal. Email: leonor@uevora.pt 
234 - As Atitudes dos Agricultores Face à Política Agrícola Comum e ao Projecto de Regadio de Alqueva

Palavras-chave: agricultura Portuguesa, PAC, atitudes, tipologias de explorações, Regime de Pagamento Único.

\begin{abstract}
The main purpose of this paper is to know farmer's attitudes face to the agricultural production, the political support and the irrigation project of Alqueva in the context of the 2003 Common Agricultural Policy (CAP) reform and the HealthCheck, in a micro-region located near the Mediterranean Sea, in the Southern region of Portugal. At the same time, this paper also aims to understand the behavioural intentions of farmers face to the technological innovation and the future of the irrigation project in this political context. Results show that the majority of farmers are a relatively homogeneous cluster about their attitudes and behavioural intentions. These farmers still maintain a productivist mindset, a strong wish to maintain an agricultural focus and they strongly reject the notions of policy liberalisation. Although they have a great potential of innovation and being aware of the importance of their contribution in the protection of the rural environment, they recognize that the future CAP, the water supply irrigation price and the conditions of access to agricultural credit, could compromise their innovation capacity in the future. The conclusions suggest that it is necessary to understand the particularities of a regional agriculture in different countries in the European Union so the policies can take place successfully. In the Portuguese case, more comprehensive studies are necessary in order to find more consistent results.
\end{abstract}

Abstract: Portuguese agriculture, CAP, attitudes, farm's typologies, Single Payment Scheme.

Classificação JEL: Q15, Q18.

\title{
1. Introdução
}

A reforma da Política Agrícola Comum (PAC) de 2003 apresentou como maior novidade o descasamento dos pagamentos diretos recebidos por produtores rurais. Desse modo, a renda garantida à unidade de produção desvinculou-se da quantidade produzida. O descasamento visa substituir todos os pagamentos diretos por uma única subvenção, o Regime de Pagamento Único (RPU) que é atribuído em função do valor histórico dos subsídios recebidos pela unidade de produção, desvinculado da quantidade produzida, mas sujeita ao cumprimento de práticas de eco-condicionalidade (OLIVEIRA e FERREIRA FILHO, 2008; Dos-Santos, 2008). No seu seguimento, a Comissão Europeia aprovou em 2008 o Health Check (HC), tendo como finalidade preparar o quadro financeiro posterior a 2013. Para esse efeito, procedeu a ajustamentos na PAC de 2003. Um dos principais ajustamentos foi o acréscimo significativo da modulação no RPU o que implicou uma diminuição progressiva do seu valor por exploração até ao 
final de 2013. Estas reformas provocarão alterações na afectação de recursos das explorações agrícolas. Como resultado, a gestão das terras agrícolas e da paisagem está sujeita ao mesmo nível de pagamento independentemente das actividades de produção praticadas. Esta mudança representa uma importante alteração no ambiente político, reforçando o papel dos agricultores na conservação da paisagem e o modo de pagamento para este papel, sem a obrigação de produzir (GORTON et al., 2008, FRAGOSO e MARQUES, 2007).

Os decisores políticos têm reconhecido que a forma como os agricultores se ajustam às mudanças da política agrícola depende parcialmente das suas atitudes (USDA, 2004). No entanto, enquanto a política agrícola mudou de uma orientação produtiva, para formas de pagamento dissociadas da produção, há pouca evidência de que as atitudes dos agricultores também se tenham ajustado (GORTON et al., 2008). Apesar disso, importantes contributos têm sido feitos por numerosos autores sobre este problema. A maioria destes trabalhos referese ao estudo das atitudes dos agricultores face às alterações da PAC de 2003 ao nível de macro-regiões ou inter-comunidades (GOMEZ-LIMON et al., 2007), países, ou mesmo englobando vários países comunitários incluindo os Novos Estados Membros (GORTON et al., 2008) entre outros. O caso mais próximo de Portugal foi estudado em Espanha por Gómez-Limón et al. (2007). No entanto, nenhum dos trabalhos focou explicitamente as atitudes dos agricultores face à PAC de 2003 e às mudanças estruturais decorrentes de investimentos públicos no regadio na agricultura portuguesa.

Apesar do Empreendimento de Fins Múltiplos de Alqueva ter sido planeado à cerca meio século atrás, sendo sucessivamente adiado e reformulado, num processo caracterizado por avanços e recuos e por sucessivas hesitações, em 1996, o XIII Governo Constitucional Português decidiu finalmente avançar com a sua construção, decorrendo a partir de então de forma faseada, prevendo-se que a sua conclusão tenha lugar em 2013. A escolha do governo português de então pela execução deste projecto entre muitas outras alternativas de desenvolvimento para o país, significou uma aposta clara no seu potencial para o desenvolvimento estratégico do Alentejo. A esta decisão não terá certamente sido alheia ao facto de esta região, apresentar, por um lado, uma tendência de despovoamento, de envelhecimento da população e de elevados índices de desemprego e, por outro, por possuir um elevado potencial para o desenvolvimento da agricultura de regadio. Esta região foi desde sempre a maior região agrícola do país e aquela onde a agricultura sempre constituiu o mais importante sector económico regional, possuindo condições edafo-climáticas e estruturais de algum modo adequadas ao desenvolvimento do regadio. Também, a situação geográfica do Alentejo apresenta uma grande proximidade com Espanha e, por essa via, com a Europa e com os outros países do Mediterrâneo.

Este projecto está actualmente em construção na região Alentejo no Sul de Portugal. Na sua vertente hidro-agrícola inclui a implementação de 110 mil novos hectares de regadio (FRAGOSO e MARQUES, 2003). 
236 - As Atitudes dos Agricultores Face à Política Agrícola Comum e ao Projecto de Regadio de Alqueva

O Perímetro de Rega do Monte Novo (PRMN), inclui-se neste grandioso projecto e será o próximo a ser concluído, possuindo muitas particularidades relativamente ao projecto de Alqueva e ao país em geral. As explorações agrícolas do PRMN são em média 4,1 e 18 vezes superiores às do Alentejo e do país, respectivamente. Trata-se de uma micro-região rural, tipicamente agrícola com características edafo-climáticas marcadamente mediterrâneas

O PRMN representa desde há muito uma enorme esperança para agricultores agrónomos e economistas na modernização da agricultura local. Os principais desafios que se colocam à sua implementação dizem respeito à capacidade de reconversão e de substituição dos actuais sistemas culturais de sequeiro por culturas regadas. A produção agrícola local tem estado nas últimas décadas maioritariamente associada aos sistemas cerealíferos e à produção pecuária de corte. Estes sistemas de exploração nos quais a produção pecuária assume um complemento de rendimento desenvolvendo-se de forma extensiva e aproveitando os sub-produtos da produção cerealífera, têm contribuído para manter a sustentabilidade do mundo rural ao nível local.

A adopção do regadio permitirá desenvolver, para além das culturas vegetais e da pecuária da corte, também um leque cultural alargado no qual se incluem as horto-industriais (beterraba, tomate, pimento) as hortifrutícolas (melão, cebola, batata), frutos (maçã, ameixeira) e as culturas mediterrânicas (vinha, olival e uva de mesa). A generalidade das novas culturas perspectivadas para esta região prevêem a utilização de tecnologias produtivas ambientalmente sustentáveis, nomeadamente, a sementeira directa e o modo de produção biológico. Por esse facto, a sustentabilidade ambiental deste projecto, estará à partida garantida no futuro.

Todo este processo de reconversão representará também um enorme desafio para os produtores rurais do PRMN, tanto em termos financeiros quanto em termos de aplicação e de desenvolvimento de novas tecnologias de produção. No entanto, localmente, há condições que facilitam este processo de transição. Isso deve-se, em grande parte, à forte motivação e empenho demonstrado ao longo da construção deste projecto por parte dos agricultores locais. Nesta região, a inexistência de água nos meses de verão tem sido até agora uma das grandes limitações produtivas que impedia o desenvolvimento de um leque cultural mais inovador e mais alargado. Do ponto de vista técnico, grande parte dos agricultores locais já possuem conhecimentos sobre as culturas a adoptar, em parte porque se tratam de sistemas culturais, perfeitamente adaptados ao Alentejo, algumas das quais já são praticadas nesta zona em regime de sequeiro ainda que com baixas produtividades, enquanto outras são praticadas por estes agricultores em áreas restritas por meio de regadio privado.

Relativamente à capacidade financeira dos produtores locais, apesar de ser diferenciada em função da estrutura agrícola local existente, todos os agricultores do PRMN se mostram bastante empenhados na sua concretização como forma de aproveitamento do potencial que o projecto de Alqueva lhes pode conferir em 
termos de competitividade futura. Os trabalhos desenvolvidos por Dos Santos (2008) mostraram que os benefícios líquidos inerentes ao projecto superam os custos de investimento, estando garantida a sua rentabilidade.

Essas características associadas à existência de água de rega criam potencialidades para tornar efectiva a diversificação da produção agrícola e a concretização do projecto de rega de Alqueva no PRMN. No entanto, esta última estará indissociavelmente ligada às atitudes dos agricultores face à PAC e às suas intenções face ao projecto de rega. Neste contexto, este artigo investiga se as tipologias de agricultores do PRMN podem ser distinguidas de acordo com suas opiniões para apoiar a política e os objectivos da agricultura, e se os diferentes valores e opiniões podem ser ligadas a diferentes intenções comportamentais para adaptar-se à reforma da PAC de 2003 e ao futuro regadio de Alqueva.

O objectivo deste trabalho é obter uma melhor compreensão sobre as atitudes dos agricultores e sobre as suas intenções comportamentais frente ao novo projecto de rega, e, consequentemente, gerar insights sobre as respostas prováveis para que os decisores públicos possam ajustar melhor as suas políticas junto dos destinatários. Para esse efeito, utiliza-se a Teoria do Comportamento Planeado (TPB), como base teórica.

\section{Fundamentação Teórica}

As atitudes têm sido consideradas importantes determinantes do comportamento (BAGOZZI, 1981). Segundo Beedel e Rehman (2000), a investigação sobre as atitudes dos agricultores e motivações no passado tenderam a ser subjectivas, e, teoricamente, um pouco imprecisas. Contudo, a utilização da Teoria do Comportamento Planeado (TCP) de Ajzen (1991), utilizada inicialmente por Willock et al. (1999a, 1999b) e por Beedel e Rehman (2000) na agricultura, possibilitou, a posteriori, o desenvolvimento de vários trabalhos nesta área. Salientam-se Solano et al. (2003), Bergevoet et al. (2004), Rehman et al. (2007) Gorton et al. (2008) e Maye et al. (2009).

O modelo de TCP de Ajzen (1991), baseia-se no pressuposto de que os seres humanos normalmente comportam-se de uma forma sensata, ou seja, têm em consideração as informações disponíveis e implícita ou explicitamente consideraram as implicações de suas acções. A teoria postula que a intenção de uma pessoa para executar ou não executar um comportamento é função directa das variáveis individuais e sociais relacionados. A componente individual baseia-se nas atitudes de uma pessoa, sendo a atitude uma disposição para reagir favorável ou desfavoravelmente a um objecto, pessoa, instituição ou evento (Kim e Hunter, 1993).

A contribuição relativa das atitudes e normas subjectivas varia de acordo com o contexto comportamental e os indivíduos envolvidos. As atitudes são 
determinadas pelas crenças sobre os resultados do desempenho do comportamento e da avaliação desses resultados esperados. A componente social referese às normas subjectivas, que são as percepções de uma pessoa sobre as pressões sociais que actuam sobre ela para realizar ou não um determinado comportamento em questão (AJZEN e FISHBEIN, 1980). As normas subjectivas são independentes da própria atitude da pessoa em relação ao comportamento em questão, mas a influência das normas subjectivas sobre uma pessoa dependerá da vontade do indivíduo para satisfazer as atitudes dos outros (GORTON et al., 2008).

Em relação às intenções dos agricultores, segundo Midgley e Dowling (1978) atendendo a que os agricultores altamente inovadores são aqueles que decidem adoptar uma inovação, independentemente da decisão dos outros, as intenções dos agricultores em adoptar novas tecnologias no regadio provavelmente estará indissociavelmente ligada à sua capacidade inovadora. Apesar de existir uma profusão de trabalhos em que as atitudes dos agricultores aparecem ligadas às intenções, nomeadamente, Rehman et al. (2003), Verhees et al. (2005) e Zarafshani et al. (2008), há igualmente um conjunto de trabalhos relativamente elevado na investigação que não está ligada a atitudes, sobre as intenções dos agricultores e sobre os seus planos futuros. Neste caso, segundo Gorton et al. (2008), os levantamentos de intenções de agricultores têm sido vistos como construtivos, porque a sua fiabilidade parece relativamente elevada, principalmente, a curto prazo. Apesar disso, os levantamentos de intenções na região mediterrânea ainda são raras, exceptuando Zarafshani et al. (2008) e parcialmente Tranter et al. (2004).

\subsection{O Perímetro de Rega do Monte Novo}

O Perímetro de Rega do Monte Novo (PRMN), zona objecto deste estudo, situa-se no Alentejo, a Sul de Portugal, próximo do mar Mediterrâneo, abrangendo cerca de 25 mil hectares dos quais, 7,1 mil serão irrigados pelo regadio público de Alqueva. O PRMN inclui 112 explorações agrícolas com superfície agrícola útil (SAU), muito superior à média do Alentejo e do país em geral.

Esta é a única micro-região Portuguesa em que esta situação se verifica. A SAU média destas explorações é de 229 ha, área 4,1 vezes superior à média das explorações do Alentejo (55 ha) e 18 vezes maior que a média de Portugal $(12,1 \mathrm{ha})$. A área média a beneficiar do regadio de Alqueva por exploração é de 63,5 ha no PRMN. Quase metade desta superfície irrigável de regadio (SIR) beneficiará explorações com SAU superior a 1,4 mil ha e perto um terço beneficiará explorações com uma dimensão entre 900 e 1,4 mil ha. Da restante SIR, 8,4\% beneficiará explorações com uma SAU de 300 a 600 hectares e apenas $7,9 \%$ beneficiará explorações com SAU inferior ou igual a 50 ha. Por seu lado, os agricultores do PRMN são mais jovens do que os do Alentejo. Os primeiros possuem em média 51 anos, enquanto o valor homólogo no Alentejo é de 56 anos (DOS-SANTOS et al., 2009). 


\section{Metodologia}

Este artigo provém de um trabalho mais exaustivo em que se procuraram conhecer as atitudes e as intenções dos agricultores do PRMN de forma a modelar o seu processo de tomada de decisão, efectuado por Dos Santos (2008), por meio de um modelo de programação matemática.

A metodologia é dividida em duas partes. Para além da recolha de dados efectuada através da aplicação de um questionário directo que possibilitou a obtenção de um vasto conjunto de informações e dados de natureza quantitativa e qualitativa utiliza-se, numa primeira fase, a análise multivariada que incluiu análise de cluster de variáveis, análise cluster de casos e a análise discriminante para classificar e identificar as empresas agrícolas do PRMN relativamente às atitudes dos agricultores.

Numa segunda fase, técnicas de estatística descritiva permitem inferir sobre as percepções e os sentimentos dos agricultores face ao modo de vida rural e aos desafios do projecto de rega de Alqueva. De seguida inclui-se, também, a utilização de estatísticas descritivas para a amostra de dados obtidos quanto à distribuição das respostas comportamentais para as escalas de Likert utilizadas, com a finalidade de inferir sobre as atitudes, intenções dos agricultores frente à PAC e ao projecto de rega.

A utilização do questionário permitiu não apenas recolher um conjunto muito profundo de informações e dados dos produtores rurais do PRMN, mas também estabelecer com eles uma relação informal, que possibilitou perceber os principais anseios, dificuldades, expectativas e esperanças com que se debatem actualmente.

A análise de cluster de variáveis teve por finalidade eliminar a autocorrelação existente entre um vasto conjunto de variáveis e seleccionar as que têm poder explicativo de forma a permitir posteriormente classificar as explorações do PRMN em grupos homogéneos. A análise cluster de casos teve por finalidade formar grupos homogéneos de explorações agrícolas no PRMN. Finalmente, a análise discriminante teve por finalidade identificar e caracterizar as explorações agrícolas representativas do PRMN.

As escalas de Likert foram baseadas em tentativas anteriores para capturar os valores dos agricultores (WILLOCK et al., 1999a e GORTON et al., 2008). A capacidade inovadora e as intenções dos agricultores face ao regadio foram efectuadas com base em Dos-Santos (2008), por meio dos dados obtidos mediante respostas fechadas e abertas.

\subsection{Recolha e análise de dados}

A aproximação ao entrevistado foi efectuada mediante informantes-chave definidos como tais pela importância da sua inserção e conhecimentos da região. 
240 - As Atitudes dos Agricultores Face à Política Agrícola Comum e ao Projecto de Regadio de Alqueva

Estes incluíram o técnico da Direç̧ão Regional de Agricultura do Alentejo responsável pela zona do PRMN e técnicos da Empresa de Desenvolvimento e Infra-estruturas de Alqueva, que é a entidade responsável pela construção da rede primária e secundária do PRMN.

A amostra foi estratificada, de forma a representar o universo em estudo. O questionário, após elaborado, foi validado através do pré-teste tendo, para esse efeito sido aplicado a agricultores do Perímetro de Rega da Meimoa no Distrito de Castelo Branco. Após a sua validação, foi aplicado a uma amostra representativa de 30 empresários agrícolas do universo em estudo (112) de acordo com Malhotra (2001).

Os inquéritos foram aplicados directamente aos produtores rurais do PRMN durante o outono e inverno de 2007. Para esse efeito, foram, em média, efectuadas duas visitas aos agricultores seleccionados na amostra. As entrevistas foram feitas utilizando-se um roteiro com perguntas que permitiam respostas fechadas e respostas abertas. Foi igualmente incluída a escala de Likert. As restantes respostas abertas foram posteriormente agrupadas e tabuladas, em função da ideia geral do pensamento apresentado pelos agricultores em relação a cada ponto que foi questionado.

As entrevistas conduzidas permitiram, para além da obtenção de um vasto conjunto de informações e dados, obter um elevado grau de confiança inquiridorinquirido e um grande envolvimento no quotidiano e no modo de vivência dos agricultores locais. Para esse efeito, foi predominantemente utilizado o método exploratório segundo o qual foram incluídas questões abertas de forma a melhor compreender os anseios, as dificuldades e as expectativas respeitantes ao projecto de rega de Alqueva.

O questionário inclui seis secções: 1) a caracterização geral do empresário e do agregado familiar, o perfil e a formação do empresário, a forma de organização das explorações agrícolas; 2 ) a estrutura da exploração; 3 ) a ocupação cultural de sequeiro e de regadio; 4) a gestão da exploração, os objectivos dos produtores e as suas principais dificuldades e expectativas face ao modo de vida rural e ao projecto de rega; 5 ) as atitudes do agricultor e as fontes de informação usadas; e, 6) as suas intenções face ao regadio de Alqueva.

\subsection{As técnicas de análise multivariada na tipificação de explorações agrícolas}

Existe um largo consenso entre os diferentes autores sobre a importância das técnicas de análise multivariada na definição de tipologias de empresas agrícolas através da análise multivariada. Estas foram inicialmente utilizadas com a finalidade de evitar erros de agregação nos modelos de programação matemática e/ou integrar aspectos psicológicos dos agricultores no processo de tomada de decisão, principalmente, quando se utilizam modelos e decisão 
multicritério, como Kobrich, Rehman e Khan (2003), López-Baldovin, GutiérrezMartin e Berbel (2006), Silva e Berbel (2007) e Gómez-Limón e Martínez (2006).

Ultimamente, têm sido usadas conjugando dados de natureza psicológica e socio-económica para estudar as atitudes de intenções dos agricultores, principalmente para prever os impactos da PAC (CABALLERO, 2001) ou para estudar a mudança tecnológica ou estrutural, e/ou a adopção de inovações por Karami (2006) e Iraizoz, Gorton e Davidova (2007) ou o desenvolvimento de estratégias de diversificação de sistemas agricultura relevantes ao nível local, utilizado por Casu et al. (2006), Daskalopoulou e Petrou (2002) entre outros.

A análise multivariada baseou-se nos trabalhos de Dos-Santos (2008), Silva e Berbel (2007), Henriques (1997), Solano et al. (2001) e Zarafshani et al. (2008). Os procedimentos incluíram a análise de cluster e a análise discriminante.

A análise de cluster é uma técnica de análise multivariada utilizada para formar grupos homogéneos, i.e., que apresentam uma grande homogeneidade de características intra-grupo e uma grande heterogeneidade inter-grupal (Hair et al., 2005). Esta técnica teve por finalidade formar grupos homogéneos de empresas agrícolas no PRMN.

Para esse efeito, foi necessário seleccionar as variáveis com poder explicativo que permitissem separar as empresas agrícolas. Apesar de tradicionalmente este processo ser efectuado com o recurso à análise factorial de componentes principais, foi utilizada a análise de cluster de variáveis de acordo com Hair et al. (1998). Esta análise teve por finalidade transformar linearmente um elevado conjunto original de variáveis num menor número de variáveis não correlacionadas sem perda de informação significativa (HAIR e al., 2005).

Os procedimentos prévios na análise de cluster incluíram a exclusão das variáveis correlacionadas, através da análise de correlação e a sua posterior standartização. A análise de cluster incluiu como medida de proximidade a Distância Euclidiana ao Quadrado e o critério de agregação utilizado foi o método de Ward. A análise de cluster de casos foi baseada nos factores obtidos na análise de variáveis. Finalmente, com o objectivo de identificar e caracterizar as explorações agrícolas representativas e de validar a análise de cluster utilizouse a análise discriminante. Esta técnica é frequentemente usada para estas finalidades (PIZZOL, 2004).

A análise discriminante consiste em encontrar combinações lineares das variáveis independentes $X_{j}$ para discriminar indivíduos pertencentes a diferentes grupos $Y_{i}$, permitindo a minimização dos erros de incorrecta classificação. É efectuada através de uma ou mais combinações lineares das variáveis independentes utilizadas $\left(X_{j}\right)$. Cada combinação linear $\left(Y_{i}\right)$ constitui uma função discriminante:

$$
Y_{i}=a_{i 0}+a_{i 1} X_{1}+a_{i 2} X_{2}+\ldots a_{i p} X_{p} \quad i=1,2, \ldots t
$$


As Atitudes dos Agricultores Face à Política Agrícola Comum e ao Projecto de Regadio de Alqueva

sendo $a_{i j}$ os coeficientes de ponderação e $X_{j}$ as variáveis discriminantes (DOSSANTOS et al., 2009 e HENRIQUES, 1997).

Usou-se o critério discriminante de Fisher para duas ou mais funções e o teste estatístico Lambda de Wilk $(\Lambda)$, tendo-se rejeitado a hipótese das médias das três funções serem iguais, porque os valores de $\Lambda$ são significativos. Os resultados conduziram às seguintes funções discriminantes:

$$
\begin{aligned}
& Z 1=-3,469+0,026 X_{2}-0,273 X_{9}-0,574 X_{10}+0,035 X_{13}+0,044 X_{14}- \\
& -0,026 X_{16}+0,043 X_{18} \\
& Z 2=-1,067+0,088 X_{1}-0,186 X_{2}-0,300 X_{9}+0,158 X_{10}-0,021 X_{16}
\end{aligned}
$$

Na função $Z 1$ as variáveis independentes com maior poder discriminatório são a superfície irrigável (SIR) de Alqueva $\left(X_{9}\right)$, o número de cabeças normais de pecuária $\left(X_{10}\right)$, a área de trigo irrigada $\left(X_{13}\right)$, a área de vinha irrigada $\left(X_{14}\right)$, os empréstimos de longo prazo $\left(X_{16}\right)$ e a formação profissional do produtor $\left(X_{18}\right)$. $\mathrm{Na}$ função $Z 2$, as variáveis independentes com maior poder discriminatório são: a idade $\left(X_{1}\right)$, a escolaridade $\left(X_{2}\right)$, a SIR de Alqueva $\left(X_{9}\right)$, o número de cabeças normais de pecuária de corte $\left(X_{10}\right)$ e os empréstimos bancários de longo prazo $\left(X_{16}\right)$.

Para conhecer as atitudes dos agricultores em relação à PAC e as suas intenções face ao regadio de Alqueva foi utilizada a escala Likert, no questionário.

\section{Resultados e Discussão}

\subsection{Resultados da análise de cluster}

Os resultados da análise de cluster de variáveis mostram que existem três factores que diferenciam as explorações agrícolas do PRMN: as suas características estruturais, a sua orientação produtiva e as características dos agricultores respectivos. As variáveis estruturais incluem a superfície agrícola útil (SAU), a SIR de Alqueva, a SIR privada, o número de tractores agrícolas e a mão-de-obra.

A orientação produtiva inclui a os sistemas de produção na situação status quo de regadio e a importância relativa da pecuária. As características do agricultor incluem a idade, a escolaridade e as fontes de informação que utilizam.

Os resultados da análise de cluster de casos evidenciam três clusters de explorações agrícolas no PRMN.

\section{Cluster I - Agricultores de menor dimensão}

Inclui as explorações agrícolas de menor dimensão, com uma SAU média entre 50 e 450 ha. Os seus proprietários são, comparativamente com os restantes 
clusters, os menos habilitados e com idades mais avançadas. Possuem em média 8 anos de escolaridade e 59 anos de idade. $\mathrm{O}$ plano de produção de regadio é formado, principalmente, por culturas arvenses e oleaginosas. Um reduzido número de explorações já pratica regadio (cereais, oleaginosas e vinha).

\section{Cluster II - Agricultores inovadores}

É formado por explorações com uma SAU entre 450 e 1,4 mil ha. Os agricultores são medianamente habilitados e relativamente jovens. Possuem em média 13 anos de escolaridade e 47 anos de idade. O plano de produção de regadio para além das culturas arvenses e oleaginosas é também formado por culturas forrageiras, vinha e olival e a pecuária por bovinos de corte.

\section{Cluster III - Empresas agrícolas consolidadas}

É formado pelas maiores empresas agrícolas neste perímetro, i.e., com uma SAU superior a 1,4 mil ha. Possuem uma estrutura fundiária e organizacional sólida e organizam-se, principalmente em Sociedades Anónimas ${ }^{6}$. Os seus gestores são o grupo mais jovem e mais habilitado. Em média têm idades inferiores a 46 anos e habilitações literárias que incluem a Licenciatura. O plano de produção de regadio é, dos três clusters, aquele que possui maiores investimentos em vinha $(1,7 \%)$ e olival de regadio $(0,3 \%)$ e, comparativamente, menores superfícies de trigo e de girassol de regadio, sendo a pecuária, no entanto, menos expressiva.

Contrariamente à hipótese inicial deste trabalho, foi verificado que os agricultores do PRMN constituem um grupo homogéneo face às suas atitudes em relação à $\mathrm{PAC}$, à mudança estrutural e ao regadio de Alqueva, uma vez que essas características não constituem um factor de diferenciação dos clusters. Este facto explica-se, a priori, por se tratar de um grupo de agricultores oriundos da mesma micro-região, regra geral, relativamente jovens face à média dos agricultores portugueses, em que a maioria vive principalmente da actividade agrícola. Estes resultados confirmam os de Dos-Santos (2008) que, na validação do modelo de programação matemática multi-período, verificou que todos os agricultores tinham idênticas atitudes face ao risco de mercado e da produção.

\subsection{As percepções dos agricultores face ao modo de vida rural}

Os resultados dos questionários permitiram, ainda, a obtenção de um vasto conjunto de informação que possibilitou analisar as percepções dos agricultores dos três clusters face ao seu modo de vida rural.

6 Forma de organização existente no Direito Comercial Português para empresas com grandes volumes de negócios com cinco ou mais accionistas. 
244 - As Atitudes dos Agricultores Face à Política Agrícola Comum e ao Projecto de Regadio de Alqueva

A Tabela 1 apresenta os aspectos inerentes à gestão da exploração. Os resultados mostram que, na generalidade, estas explorações são geridas pelos seus proprietários, os quais, na sua grande maioria, são também responsáveis pelas decisões estratégicas de longo prazo.

Os produtores agrícolas dos clusters II e III dedicam-se maioritariamente à actividade agrícola, enquanto nas explorações de menores dimensões, como é o caso das explorações do cluster I, essa percentagem já é também desempenhada a tempo parcial. Tal fato deve-se à menor dimensão das explorações e, consequentemente, à dificuldade destas conseguirem assegurar um rendimento global indispensável à sobrevivência dos produtores, que possuem, regra geral, outras formas alternativas de rendimentos, no qual se incluem as pensões e a actividade comercial.

A grande maioria dos agricultores encontra-se nesta actividade principalmente por ser aquela em que se sentem realizados profissionalmente. A maioria destas explorações agrícolas resultou de herança familiar nos clusters I e II. No cluster III provêm, principalmente, de novos investimentos efectuados. A totalidade dos agricultores encontra-se já numa fase estabilizada da agricultura, mas pretende manter-se na actividade no futuro.

Tabela 1. Aspectos referentes à gestão da exploração.

\begin{tabular}{lccc}
\hline \multicolumn{1}{c}{ A gestão da exploração (\%) } & \multicolumn{3}{c}{ Cluster } \\
\cline { 2 - 5 } & I & II & III \\
\hline O gestor da exploração é: & 100 & 92 & 75 \\
$\quad$ - o próprio & & & \\
Quem toma as decisões de longo prazo da exploração & 100 & 92 & 50 \\
$\quad$ - o próprio & & & \\
Tempo dedicado à actividade agrícola & 16,7 & - & - \\
$\quad$ - de 25 a 50 & 58,3 & 23 & - \\
- de 51 a 75 & 25 & 77 & 100 \\
$\quad$ - de 76 a 100 & 66,7 & 100 & 100 \\
Possui formação profissional agrícola: sim & & & \\
Origem do rendimento da exploração & 25 & 77 & 100 \\
$\quad$ - exclusivamente da actividade agrícola & 75 & 23 & - \\
$\quad$ - principalmente da actividade da exploração (mais de 50\%) & & & \\
Desenvolve actividade agrícola porque: & 58,3 & 75 & 75 \\
$\quad$ - é a actividade onde se realiza do ponto de vista profissional & 75 & 61,5 & - \\
$\quad$ - foi uma herança familiar & & & \\
Considera-se um empresário agrícola & 91,6 & 100 & 100 \\
$\quad$ - numa fase estabilizada mas deseja manter-se na actividade & 8,3 & - & - \\
- numa fase final e deseja retirar-se da actividade & &
\end{tabular}

Fonte: Resultados dos questionários, 2007. 
Na Tabela 2, são apresentadas as principais dificuldades face ao modo de vida rural actual dos produtores agrícolas do PRMN. Os resultados mostram que os agricultores dos clusters I e II não se consideram suficientemente informados sobre as actuais medidas de apoio no âmbito da PAC. Sugere-se, assim, uma efectiva assistência técnica e extensão rural proporcionada pelos serviços do Ministério da Agricultura das Pescas e do Desenvolvimento Rural Português para estes agricultores. Apesar disso, estes consideram que dominam a área da produção agrícola e que, do ponto de vista financeiro, não têm grandes limitações - à excepção dos agricultores de reduzidas dimensões, para os quais se sugere uma política efectiva de crédito rural ajustada às suas necessidades.

Tabela 2. As principais dificuldades face à actividade agrícola.

\begin{tabular}{|c|c|c|c|}
\hline \multirow{2}{*}{ Dificuldades e anseios face à actividade agrícola } & \multicolumn{3}{|c|}{ Cluster } \\
\hline & $\mathbf{I}$ & II & III \\
\hline \multicolumn{4}{|l|}{$\begin{array}{l}\text { Considera-se suficientemente informado sobre as medidas de apoio } \\
\text { no âmbito da PAC: }\end{array}$} \\
\hline Sim & 7 & 41 & 100 \\
\hline \multicolumn{4}{|l|}{ Quais as áreas que mais o preocupam na sua actividade agrícola: } \\
\hline - área técnica agrícola & 14 & 7 & - \\
\hline - área comercial & 100 & 92 & 92 \\
\hline $\begin{array}{l}\text { - área institucional (maiores exigências no cumprimento das medi- } \\
\text { das no âmbito da PAC) }\end{array}$ & 93 & 59 & 42 \\
\hline - área financeira & 49 & 21 & - \\
\hline \multicolumn{4}{|l|}{ A médio/longo prazo espera: } \\
\hline - ter um rendimento estável & 50 & 51 & 25 \\
\hline - aumentar o rendimento & 25 & 49 & 75 \\
\hline - diminuir o rendimento & 25 & - & - \\
\hline \multicolumn{4}{|l|}{$\begin{array}{l}\text { As principais dificuldades com que se debate actualmente na sua ex- } \\
\text { ploração são: }\end{array}$} \\
\hline - diminuição dos preços dos principais produtos produzidos & 41 & 43 & 23 \\
\hline - dificuldades de comercialização dos produtos produzidos & 92 & 71 & 59 \\
\hline - diminuição das ajudas comunitárias à produção & 33,3 & 21,5 & 10,3 \\
\hline - diminuição dos rendimentos obtidos & 31,3 & 23 & 25 \\
\hline - factores de produção a preços mais elevados & 41 & 33,3 & 25 \\
\hline - dificuldades financeiras para efectuar novos investimentos & 33 & 15,3 & - \\
\hline - limitações de idade do próprio empresário & 25 & - & - \\
\hline \multicolumn{4}{|l|}{ Enquanto produtor agrícola sente-se: } \\
\hline - motivado & 67 & 84,7 & 100 \\
\hline - acompanhado pelos decisores públicos & 3,3 & 6,6 & 25 \\
\hline \multicolumn{4}{|l|}{ Caso tenha sucessores: } \\
\hline - terá orgulho que eles continuem na agricultura & 25 & 75 & 100 \\
\hline - preferia que eles tivessem emprego fora da agricultura & 75 & 25 & 25 \\
\hline
\end{tabular}

Fonte: Resultados dos questionários, 2007. 
246 - As Atitudes dos Agricultores Face à Política Agrícola Comum e ao Projecto de Regadio de Alqueva

A comercialização da produção agrícola e as exigências e normativas institucionais que decorrem da adopção da PAC são consideradas aquelas em que, regra geral, os produtores do PRMN têm mais preocupações. A globalização, as exigências crescentes da qualidade da produção agrícola, aliadas às dificuldades de comercialização e de cumprimento de rigorosas regras comunitárias nos domínios da eco-condicionalidade, também conduzem, conforme relatam estes produtores, a dificuldades acrescidas na gestão das suas explorações. Estes aspectos agravam-se, segundo eles, por não se sentirem acompanhados pelos decisores públicos.

Apesar das limitações e dificuldades com que se debatem, os agricultores do PRMN pretendem aproveitar o futuro regadio de Alqueva. Para esse efeito pretendem, de uma forma geral, aumentar o investimento na exploração, o que lhes permitirá intensificar e diversificar a produção agrícola actual. No entanto, existem algumas dificuldades que são necessárias ultrapassar, como o modo de funcionamento do futuro PRMN, que os três clusters de agricultores dizem desconhecer como se irá processar, respectivamente, para $92 \%, 76 \%$ e $75 \%$ dos agricultores dos clusters I, II e III. Além disso, a comercialização da produção agrícola, o custo da água de rega e a evolução da PAC constituem as principais preocupações e incertezas respeitantes ao novo projecto de regadio.

Tabela 3. Principais expectativas dos agricultores do PRMN face ao projecto de regadio de Alqueva.

\begin{tabular}{llll}
\hline \multirow{2}{*}{ Expectativas e desafios face ao projecto de rega } & \multicolumn{2}{c}{ Cluster } \\
\cline { 2 - 3 } & I & II & III \\
\hline
\end{tabular}

Com a implementação do regadio pretende:

- abandonar a agricultura

$17 \quad-\quad-$

- aumentar o investimento na exploração

$\begin{array}{lll}67 & 71 & 100\end{array}$

- intensificar as tecnologias de regadio

$\begin{array}{lll}71 & 75 & 100\end{array}$

- diversificar as actividades agrícolas de regadio

$\begin{array}{lll}77 & 91 & 92\end{array}$

- manter a situação actual

As principais preocupações em relação à adopção do regadio de Alqueva são:

- incerteza quanto ao funcionamento do perímetro de rega

- dificuldades de comercialização da produção

$92 \quad 76 \quad 75$

- água de rega a um preço elevado

$87 \quad 57 \quad 75$

- políticas agrícolas que não favorecem a produtividade

$5951 \quad 50$

- dificuldades técnicas e falta de informação relativamente às culturas de regadio

27

Fonte: Resultados dos questionários, 2007. 


\subsection{Resultados da análise discriminante}

Com a finalidade de compreender a razão pela qual estes agricultores não se diferenciam entre si face às suas atitudes em relação à PAC, efectuou-se a análise discriminante, a qual confirmou que mais de $90 \%$ das explorações se encontravam bem classificadas.

Com base no cálculo da Distância de Mahalanobis ao Quadrado, determinaram-se as três empresas A, B e C representativas, correspondentes aos grupos I, II e III, respectivamente. A Tabela 4 apresenta as principais características dessas empresas. Estes resultados confirmam a relativa homogeneidade das atitudes dos agricultores do PRMN.

Tabela 4. Características das empresas agrícolas representativas dos três clusters.

\begin{tabular}{|c|c|c|c|}
\hline \multirow{2}{*}{$\begin{array}{l}\text { Características das } \\
\text { empresas }\end{array}$} & \multicolumn{3}{|c|}{ Empresas agrícolas representativas } \\
\hline & A-I & B-II & C-III \\
\hline SAU total (ha) & 350 & 1334 & 1775 \\
\hline SIR regadio privado (ha) & 116 & 250 & 477 \\
\hline SIR regadio Alqueva (ha) & 50 & 150 & 615 \\
\hline Forma de exploração & conta própria & conta própria & conta própria \\
\hline Forma de organização & nome individual & nome individual & sociedade \\
\hline Gestor: idade (anos) & 55 & 45 & 44 \\
\hline Habilitações escolares (anos) & 9 & 12 & 17 \\
\hline $\begin{array}{l}\text { Actividades actuais de regadio } \\
\text { (\% SAU) }\end{array}$ & $\begin{array}{l}\text { girassol (18), } \\
\text { trigo }(33) \text { e } \\
\text { milho }(5,7)\end{array}$ & $\begin{array}{c}\text { girassol }(6,7), \\
\text { trigo }(18,7), \\
\text { milho forrageiro }(1,1) \\
\text { e vinha }(3)\end{array}$ & $\begin{array}{c}\text { girassol }(8,8), \\
\text { trigo }(13,4), \mathrm{e} \\
\text { milho }(4,4)\end{array}$ \\
\hline Pecuária (bovinos de corte) $(\mathrm{CN})$ & 120 & 250 & - \\
\hline
\end{tabular}

Fonte: Resultados da análise discriminante (Dos Santos, 2008).

Estas empresas são muito similares, quer nas suas características, quer nas dos seus proprietários. Todas são explorações comerciais de grandes a muito grandes dimensões, exploradas por conta própria, cujos agricultores vivem da actividade agrícola. Os agricultores por seu turno são medianamente habilitados e relativamente jovens e praticamente todos eles são os responsáveis pela gestão das suas explorações.

\subsection{Resultados das atitudes dos agricultores}

A Tabela 5 e a Tabela 6 apresentam os níveis médios das respostas obtidas por meio da escala de Likert no questionário aplicado aos agricultores do PRMN respeitante às suas atitudes. 
248 - As Atitudes dos Agricultores Face à Política Agrícola Comum e ao Projecto de Regadio de Alqueva

Tabela 5. Estatísticas descritivas da média dos níveis da escala de Likert referente às atitudes dos agricultores do PRMN

\begin{tabular}{|c|c|c|c|c|c|}
\hline Atitudes dos agricultores & 1 & 2 & 3 & 4 & 5 \\
\hline \multicolumn{6}{|l|}{ Atitudes relativas ao mercado } \\
\hline $\begin{array}{l}\text { Um agricultor competitivo consegue competir no } \\
\text { mercado livre sem qualquer apoio da PAC }\end{array}$ & - & 16,7 & 10 & 40 & 33,3 \\
\hline $\begin{array}{l}\text { As minhas capacidades de gestor agrícola permitir- } \\
\text { me-ão manter um nível adequado de rendimento } \\
\text { independentemente da política agrícola que tenha } \\
\text { lugar }\end{array}$ & 16,7 & 10 & 3,3 & 66,7 & 3,3 \\
\hline \multicolumn{6}{|l|}{ Medidas de apoio à agricultura } \\
\hline $\begin{array}{l}\text { Os agricultores não devem receber qualquer subsídio } \\
\text { à quantidade de produto produzida }\end{array}$ & - & 3,3 & 20 & 20 & 56,7 \\
\hline $\begin{array}{l}\text { Os agricultores não devem receber qualquer subsídio } \\
\text { à superfície semeada }\end{array}$ & - & 10 & 13,3 & 33,3 & 43,3 \\
\hline $\begin{array}{l}\text { Os agricultores não devem receber qualquer subsídio } \\
\text { ao rendimento }\end{array}$ & - & 10 & 26,7 & 46,7 & 16,7 \\
\hline $\begin{array}{l}\text { Os agricultores não devem receber qualquer subsídio } \\
\text { relacionado com a produção de bens ambientais }\end{array}$ & - & 20 & 10 & 60 & 10 \\
\hline \multicolumn{6}{|l|}{ Foco agrícola } \\
\hline Os agricultores só devem produzir alimentos e fibras & 3,3 & 33,3 & 16,7 & 40 & 6,7 \\
\hline $\begin{array}{l}\text { A terra agrícola só deve ser usada para a produção } \\
\text { agrícola }\end{array}$ & 60 & 20 & 10 & 10 & - \\
\hline $\begin{array}{l}\text { Os agricultores devem produzir bens ambientais e } \\
\text { paisagens protegidas }\end{array}$ & 13,3 & 40 & 16,7 & 10 & 20 \\
\hline $\begin{array}{l}\text { A agricultura é um trabalho mais gratificante em ter- } \\
\text { mos de qualidade de vida, independência, estilo de } \\
\text { vida, do que é em termos de dinheiro }\end{array}$ & 6,7 & 63,3 & 13,3 & 16,7 & - \\
\hline
\end{tabular}

\section{Normas subjectivas sobre os aspectos relacionados com a agricultura}

\begin{tabular}{lrrrrr}
$\begin{array}{l}\text { Os amigos e a família pensam que os agricultores ape- } \\
\text { nas produzem produtos agrícolas }\end{array}$ & & 10 & 16,7 & 60 & 13,3 \\
$\begin{array}{l}\text { Amigos e familiares pensam que os agricultores prote- } \\
\text { gem a paisagem e produzem bens ambientais }\end{array}$ & 6,7 & 43,3 & 26.7 & 20 & 3,3 \\
$\begin{array}{l}\text { Amigos e familiares acham que o apoio da PAC deve } \\
\text { ajudar os produtores a manter-se na agricultura }\end{array}$ & 6,7 & 60 & 13,3 & 16.7 & 3,3 \\
$\begin{array}{l}\text { Amigos e familiares acham que o projecto de Alqueva } \\
\text { pode ajudá-los a melhorar a competitividade agrícola }\end{array}$ & 10 & 63,3 & 13,3 & 10 & 3,3 \\
\hline
\end{tabular}

Escala de Likert: 1. Concorda fortemente; 2. concorda; 3. não concorda nem discorda; 4. discorda; 5 . discorda fortemente.

Fonte: Adaptado de Gorton et al. (2008) e de Dos Santos (2008).

Os resultados das respostas para cada item da escala de Likert revelam que a maioria dos agricultores se opõe fortemente à abertura de mercados e à liberalização política. Aproximadamente três quartos discordam ou discordam 
fortemente que seja possível manter a sua competitividade agrícola num mercado livre. Sobre o desaparecimento das medidas de apoio à agricultura, nomeadamente, subsídios à produção, sustentação dos preços dos produtos e ajudas ao rendimento, aproximadamente a mesma percentagem discorda ou discorda fortemente da sua aplicação. Os agricultores consideram que as mesmas são imprescindíveis à sua manutenção na actividade agrícola e que delas depende a sua competitividade. Por outro lado, o foco agrícola é muito forte, cerca de $80 \%$ dos agricultores consideram que a terra agrícola deve ser utilizada para a produção agrícola. No entanto, afirmam que as suas funções vão muito para além de produtores agrícolas. Mais de metade concorda que também protege a paisagem, que cria bens ambientais. Reforçam que a sua permanência na actividade vai muito para além do rendimento agrícola, salientando tratar-se de uma actividade aliciante, muito autónoma e ao ar livre. Apesar disso, a maioria dos agricultores $(80 \%)$ considera que a PAC lhes impõe demasiadas restrições na sua actividade.

Praticamente a totalidade da amostra concorda ou concorda fortemente que a política futura do preço da água poderá colocar em causa a competitividade do regadio local, nomeadamente, por meio do aumento do custo da água de irrigação. Embora o PRMN ainda não se encontre totalmente construído, estes agricultores têm ideias bem definidas sob a forma como gostariam que a água de rega lhes fosse distribuída no futuro. A maioria prefere que a água de irrigação lhes seja fornecida sob pressão. Argumentam que isso implicaria menores investimentos em sistemas de armazenamento e bombagem da água, principalmente para aqueles que já praticam a irrigação. Caso contrário, i.e., se a distribuição da água ocorresse por gravidade, acarretaria elevados investimentos em sistemas de bombagem e de armazenamento da água de rega. Apesar disso, argumentam que esta última hipótese de fornecimento de água, a concretizar-se, não comprometerá a sua capacidade financeira nesses investimentos e no regadio em geral, apesar de implicar custos adicionais.

Relativamente à necessidade sentida pelos agricultores em relação ao apoio técnico e à extensão ou rural no regadio, mais de metade dos inquiridos concorda ou concorda totalmente com a sua existência, um terço dos agricultores não concorda nem discorda, principalmente porque já pratica ou praticou culturas de regadio e pretende dar-lhes continuidade no futuro. Apesar disso, mostram-se pouco receptivos em relação ao seu pagamento. 
250 - As Atitudes dos Agricultores Face à Política Agrícola Comum e ao Projecto de Regadio de Alqueva

Tabela 6. Estatísticas descritivas da média dos níveis da escala de Likert referente às atitudes dos agricultores do PRMN.

\begin{tabular}{|c|c|c|c|c|c|}
\hline Atitudes dos agricultores & 1 & 2 & 3 & 4 & 5 \\
\hline \multicolumn{6}{|l|}{ Motivação para tomar decisões } \\
\hline $\begin{array}{l}\text { Quando tomo decisões acerca da agricultura consulto } \\
\text { a minha família e/ou sócios e/os meus amigos }\end{array}$ & 6,7 & 63,3 & 3,3 & 27,7 & - \\
\hline $\begin{array}{l}\text { As opiniões da minha família/sócios e/ou dos amigos } \\
\text { vêm sempre em primeiro lugar }\end{array}$ & - & 40 & 10 & 46,7 & 3,3 \\
\hline \multicolumn{6}{|l|}{ Controle da PAC e do regadio de Alqueva } \\
\hline $\begin{array}{l}\text { O sistema de subsídios da PAC impõe demasiadas res- } \\
\text { trições nos meus planos futuros da agricultura }\end{array}$ & 50 & 30 & 16,7 & 3,3 & - \\
\hline $\begin{array}{l}\text { A política de preços da água no regadio pode compro- } \\
\text { meter os meus planos de irrigação futuros }\end{array}$ & 40 & 53,3 & 6,7 & - & - \\
\hline $\begin{array}{l}\text { A distribuição de água por gravidade poderá com- } \\
\text { prometer a minha capacidade financeira para novos } \\
\text { investimentos }\end{array}$ & - & 16,7 & 40 & 43,3 & - \\
\hline $\begin{array}{l}\text { Eu necessito de apoio e informação técnica nas cultu- } \\
\text { ras irrigadas }\end{array}$ & 10 & 46,7 & 33,3 & 6,7 & 3,3 \\
\hline $\begin{array}{l}\text { Estou receptivo a pagar a informação técnica (exten- } \\
\text { são rural) que necessito }\end{array}$ & 3,3 & 46,7 & 33,3 & 16,7 & \\
\hline $\begin{array}{l}\text { Eu tenho que manter minha empresa agrícola sempre } \\
\text { (para garantir a sucessão ou por outros motivos) }\end{array}$ & 23,3 & 36,7 & 13,3 & 20 & 6,7 \\
\hline
\end{tabular}

Escala de Likert: 1. Concorda fortemente; 2. concorda; 3. não concorda nem discorda; 4. discorda; 5 . discorda fortemente.

Fonte: Adaptado de Gorton et al. (2008) e de Dos Santos (2008).

Mais de dois terços dos agricultores querem permanecer na agricultura, porque são donos das suas terras, e por razões de sucessão (a maioria deles tem um sucessor na agricultura).

Sobre as normas subjectivas relativas à família e aos amigos, também existe uma concordância forte entre todos os agricultores PRMN. Cerca de três quartos acreditam que os amigos e a família estão cientes de que suas funções vão muito além de produtores, mas que o apoio da PAC é essencial para permanecer na agricultura no futuro.

Embora os agricultores assumam que o processo de tomada de decisão é influenciado pela família e/ou por membros das suas empresas agrícolas (dois terços da amostra), tal deve-se, em parte, à forma de organização das mesmas que inclui as sociedades. Simultaneamente, quase três quartos dos agricultores acreditam que os amigos e a família têm muitas expectativas sobre a competitividade futura do projecto de Alqueva. Isso significa que o projecto de Alqueva é desejado nessa região, não só pelos agricultores, mas também pelos seus familiares e amigos. 


\subsection{A capacidade inovação e as intenções dos agricultores}

A capacidade de inovação destes agricultores é muito elevada. Cerca de dois terços implantaram nos últimos seis anos pelo menos três novas culturas, (principalmente olival, vinha e beterraba) e novas tecnologias de produção (sementeira directa, colheita mecânica de azeitona e vinha e sistemas de irrigação), efectuando para tal projectos de investimento aprovados e financiados por fundos comunitários e por empréstimos de longo prazo. Cerca de um terço destes agricultores utiliza mais de três fontes de informação agrícola, sendo que 36,7 \% possui Licenciatura em ciências agrárias. O regadio privado já é, ou foi praticado nos últimos seis anos por $86 \%$ dos agricultores.

Relativamente às intenções dos agricultores face ao regadio, a totalidade pretende aproveitar a superfície irrigável de Alqueva nos próximos três anos, embora se mostrem apreensivos face ao preço da água do regadio público. Cerca de $47 \%$ do total da amostra pretende adquirir mais terra e $80 \%$ deseja aumentar a superfície de regadio nos próximos cinco anos. No entanto, existem diferenças significativas entre os clusters. Enquanto nos grupos II e III, os agricultores se manifestam totalmente favoráveis à aquisição de terra, no cluster I apenas $58 \%$ da amostra manifestou essa intenção. Estes agricultores mostram um forte foco nas actividades agrícolas inovadoras no regadio. Quase dois terços deles têm intenções de realizá-las nos próximos cinco anos. Apesar disso, também existem diferenças significativas entre os clusters. Assim, embora esta intenção seja partilhada por todos os elementos do grupo III, a mesma apenas é partilhada por cerca de três quartos dos agricultores do cluster II e por metade dos agricultores do cluster I. Isto significa que são as empresas agrícolas de maiores dimensões, aquelas que mais facilmente conseguem adoptar novas inovações no regadio. Essa situação de maior apoderamento dos meios de produção coloca as empresas à frente da estrutura familiar dos clusters I e II. Por conseguinte, são as empresas do cluster III cujas economias de escala, vão, à partida retirar maiores proveitos do aproveitamento do regadio de Alqueva. Assim, sugere-se uma revisão e um aprofundamento das políticas de concessão de crédito rural para que esta proporcione maiores oportunidades de investimento aos produtores de menores dimensões estruturais.

Aproximadamente dois terços da amostra pretende aumentar a produção de bovinos de corte e introduzir novas culturas de irrigação: forragens (73\%), olival (50 \%), vinha $(17,7 \%)$ e hortícolas $(16,7 \%)$. A análise por clusters mostra que existem diferenças entre eles, principalmente em função da sua estrutura empresarial. Assim, as culturas mediterrânicas olival e a vinha são os investimentos preferidos, principalmente, nos clusters II e III, enquanto a produção pecuária de corte associada à produção de forragens representa uma intenção transversal entre os três clusters.

Apesar de se encontrarem muito preocupados com a comercialização da sua produção agrícola no futuro cerca de 76,7 \% encontram-se bastante receptivos à introdução de 
252 - As Atitudes dos Agricultores Face à Política Agrícola Comum e ao Projecto de Regadio de Alqueva

novas tecnologias de produção, principalmente como uma forma de reduzir a mão-deobra (60\%), por considerarem que esta é pouco qualificada e que lhes acarreta elevados custos, para $80 \%$ dos inquiridos. Apesar destes agricultores expressarem opiniões precisas sobre as suas intenções a curto prazo nas suas explorações, mais da metade $(56,7 \%)$ refere que as dificuldades de acesso ao crédito lhes poderá comprometer os seus planos futuros. Refira-se que os agricultores mais preocupados sobre esta questão pertencem, principalmente, ao grupo I, e, portanto, são as pequenas explorações agrícolas, ou seja, aquelas que, à priori, mais necessitam de apoio do crédito agrícola. Esses resultados mostram que, em geral, os agricultores do PRMN tem intenções diferentes no que diz respeito à inovação, porque as suas explorações têm capacidades financeiras diferenciadas. Isso implica diferentes opções futuras de investimento e de produção, apresentando por isso diferentes intenções em relação ao futuro projecto de Alqueva e à PAC.

\section{Conclusões}

Este artigo visa conhecer as atitudes e as intenções dos agricultores no Perímetro de Rega do Monte Novo, no Sul de Portugal, em relação à produção agrícola, ao apoio político, à inovação e ao projecto de rega de Alqueva, no contexto da PAC e 2003 e do Health-Check. Para esse efeito foi aplicado um questionário directo a uma amostra representativa de explorações agrícolas. De seguida técnicas de análise multivariada, nomeadamente, análise de cluster e análise discriminante, permitiram tipificar e identificar as empresas representativas desta micro-região, tendo sido formados três clusters e três empresas tipo, respectivamente. Estes resultados confirmaram que estas tipologias formam um grupo muito homogéneo de empresas no que diz respeito às suas atitudes em relação à $\mathrm{PAC}$ e ao projecto público de rega, porque essas variáveis não constituem um factor de diferenciação na análise de cluster. Este facto justificase por se tratar de um grupo de agricultores com sistemas de produção e condições agro-climáticas muito similares em que todos são oriundos da mesma região, conforme confirmaram os resultados da análise discriminante. Com base em técnicas de estatística descritiva foram analisadas as percepções dos agricultores face ao modo de vida rural. Esta análise mostrou que os agricultores se encontram na actividade agrícola por ser aquela na qual se sentem realizados. As actuais explorações foram, grande parte obtidas através de herança familiar. Os produtores rurais encontram-se numa fase de estabilidade económica. Apesar disso, possuem elevadas expectativas relativamente aos benefícios que o projecto de rega de Alqueva lhes pode proporcionar no futuro, esperando por essa via não apenas aumentar mas também diversificar a actividade agrícola. Os seus maiores anseios e dificuldades dizem respeito ao modo de funcionamento do PRMN, à política de preços da água do regadio público, à comercialização da 
produção agrícola assim como à adopção da PAC. Com a finalidade de conhecer quais as atitudes e intenções destes agricultores em relação à PAC de 2003, ao Health-Check e ao projecto de rega foram utilizadas técnicas de estatística descritiva efectuadas com base na escala de Likert constante no questionário aplicado para além de questões abertas e fechadas. Estes resultados provaram que apesar de se tratar de um grupo de agricultores com elevada capacidade de inovação, mantêm ainda uma mentalidade muito produtivista e um foco agrícola forte rejeitando veementemente as noções de liberalização política e de abertura de mercados. Apesar disso, pretendem aproveitar o regadio e introduzir inovações tecnológicas a curto prazo, embora reconheçam existir limitações que podem impedir essas decisões, como as dificuldades de acesso ao crédito. Sugere-se assim, a revisão das políticas de concessão de crédito rural, no sentido de terem em consideração as necessidades das explorações agrícolas de menores dimensões. Salienta-se que no geral, este trabalho fornece uma ferramenta empírica útil para os decisores políticos em causa melhorarem a receptividade e a participação dos produtores locais em projectos desta natureza. No entanto são necessários estudos mais abrangentes para o projecto de rega público de Alqueva e para a situação Portuguesa de forma a encontrar resultados mais consistentes.

\section{Referências Bibliográfias}

AJZEN, I.. The theory of planned behaviour, Organisational Behaviour and Human Decision Processes 20, p. 179-211, 1991.

AJZEN, I.; FISHBEIN, M. Understating attitudes and predicting social behaviour. Prentice-Hall, Inc., Englewood Cliffs, 1980.

BAGOZZI, R. P. Attitudes, intentions and behaviour: A test of some key hypothesis. Journal of Personality and Social Psychology 41, p. 607-627, 1981.

BEEDELL, J.; REHMAN, T. Using social-psychology models to understand farmers' conservation behaviour. Journal of Rural Studies 16 (1) p. 117-127, 2000.

BERGEVOET, R. H. M.; ONDERSTEIJN, C. J. M.; SAATKAMP, H. W.; VAN WOERKUM, C. M. J.; HUIRNE, R. B. M. Entrepreneurial behaviour of Dutch dairy farmers under a milk quota system: goals, objectives and attitudes. Agricultural Systems 80 (1), p. 1-21, 2004.

CABALLERO, R. Typology of cereal-sheep farming systems in Castile-La Mancha (south-central Spain) Agricultural Systems 68:(3), p. 215-232, 2001.

CASU, S.; MOLlE, G.; DECANDIA, M.; LIGIOS, S.; CARTA, A. Using cluster analysis to characterize the goat farming system in Sardinia. Livestock Science 104:(1-2), p. 63-76, 2006. 
254 - As Atitudes dos Agricultores Face à Política Agrícola Comum e ao Projecto de Regadio de Alqueva

EUROBAROMETERO. Farmers' attitudes towards the CAP, eurobarometer flash study No.86, DG Agriculture, 2000, Mimeo.

DASKALOPOULOU, I.; PETROU, A. Utilising a farm typology to identify potential adopters of alternative farming activities in Greek agriculture. Journal of Rural Studies 18:(1), p. 95-103, 2002.

DOS-SANTOS, M. J. P. L. Análise da competitividade do regadio de Alqueva: O caso do Perímetro de Rega do Monte Novo. Tese de doutoramento, Universidade de Évora, Évora, 2008.

DOS-SANTOS, M. J. P. L.; HENRIQUES, P. D. S.; FRAGOSO, R. M. S.; SILVACARVALHO, M. L. P. V. A competitividade do regadio de Alqueva: O caso do Perímetro de Rega do Monte Novo a Sul de Portugal. XLVII SOBER - Congresso da Sociedade Brasileira de Economia, Administração e Sociologia Rural. Brasil, 2009.

FRAGOSO, R. M.; MARQUES, C. F. Perspectives for the irrigated agriculture in Alentejo. New Medit - Mediterranean Journal of Economics, Agriculture and Environment 2, p. 21-26, 2003.

FRAGOSO, R. M. S. C.; MARQUES, C. A Competitividade do regadio em Portugal no contexto da nova Política Agrícola Comum: O caso de uma exploração agrícola no Alentejo. Revista de Economia e Sociologia Rural 45, p. 49-70, 2007.

GÓMEZ-LIMÓN, J. A.; MARTÍNEZ, Y. Multi-criteria modelling of irrigation water market at basin level: A Spanish case study. European Journal of Operational Research 173:(1), p. 313-336, 2006.

GÓMEZ-LIMÓN, J. A. R.; MOYANO, E. E.; VERA, T. E.; GARRIDO, F. F. E. Actitudes y percepciones sociales sobre la multifuncionalidad agraria: el caso de Andalucía. Revista de Estudios Regionales 80, p. 345-356, 2007.

GORTON, M.; DOUARIN, E.; DAVIDOVA, S.; LATRUFFE, L. Attitudes to agricultural policy and farming futures in the context of the 2003 CAP reform: A comparison of farmers in selected established and New Member States. Journal of Rural Studies 24, p. 322-336, 2008.

HAIR, J. F.; ANDERSON, R. E.; TATHAM, R. L.; BLACK, W. C. Multivariate data analysis (Fifth Edition). Prentice Hall International, New Jersey, 1998.

HAIR, J. R.; BLACK, B.; BABIN, B.; ANDERSON, R. E. Multivariate data analysis. $6^{\text {th }}$ Edition, Maxwell MacMillan Editions, 2005.

HENRIQUES, P. D. S. Technical efficiency and changes in Alentejan farming systems. PhD Thesis. University of Reading. Reading. UK, 1997.

IRAIZOZ, B.; GORTON, M.; DAVIDOVA, S. Segmenting farms for analysing agricultural trajectories: a case study of the Navarra region in Spain. Agricultural Systems 93: (1-3), p. 143-169, 2007. 
KARAMI, E. Appropriateness of farmers' adoption of irrigation methods: The application of the AHP model Department of Agricultural Extension, University, Shiraz, Iran. Agricultural Systems 87: (1), p. 101-119, 2006.

KIM, M. S.; HUNTER, J. E. Attitude-behaviour relations: A meta-analysis of attitudinal relevance and topic. Journal of Communication 43(1), p. 101-142, 1993.

KOBRICH, C.; REHMAN, T.; KHAN, M. Typification of farming systems for constructing representative farm models: two illustrations of the application of multi-variate analyses in Chile and Pakistan. Agricultural Systems 76:(1), p. 141-157, 2003.

LÓPEZ-BALDOVIN, M. J.; GUTIÉRREZ-MARTIN, C.; BERBEL, J. Multicriteria and multiperiod programming for scenario analysis in Guadalquivir river irrigated farming Journal of the Operational Research Society 57: (5), p. 499-509, 2006.

MALHOTRA, N. K. Pesquisa de marketing: Uma orientação aplicada. 3. ed. Porto Alegre, Bookman, 2001.

MAYE, D.; ILBERY, B.; WATTS, D. Farm diversification, tenancy and CAP reform: Results from a survey of tenant farmers in England. Journal of Rural Studies 25:(3), p. 333-342, 2009.

MIDGLEY,D.F.; DOWLING, G. R. Innovativeness - concept and its measurement. Journal of Consumer Research 4:( 4), p. 229-242, 1978.

OLIVEIRA, S. J. M.; FERREIRA FILHO, J. B. S. A Expansão da União Européia em 2004 e seus impactos sobre o agronegócio Brasileiro. 2005. Revista de Economia e Sociologia Rural. 46, (4), p. 937-967, 2008.

PIZZOL, S. J. Combinação de grupos focais e análise discriminante: um método para tipificação de sistemas de produção agropecuária. Revista Economia e Sociologia Rural 42:(3), p. 451-468, 2004.

REHMAN, T.; MCKEMEY; YATES, C. M.; COOKE, R. J. K.; GARFORTH, C.; TRANTER, R. B.; PARK, J. R.; DORWARD, P. T. Identifying and understanding factors influencing the uptake of new technologies on dairy farms in SW England using the theory of reasoned action. Agricultural Systems 94:(2), p. 281293, 2007.

REHMAN, T.; MCKEMEY, K.; GARFORTH, C.; HUGGINS, R.; YATES, C.; COOK, R.; TRANTER, R.; PARK, J.; DORWARD, P. Theory of Reasoned Action and its integration with economic modelling in linking farmers' attitudes and adoption behaviour - an illustration from the analysis of the uptake of livestock technologies in the South West of England.In Proceeding of the 14th International Farm Management Congress, Western Australia, p. 1-19, 2003. 
As Atitudes dos Agricultores Face à Política Agrícola Comum e ao Projecto de Regadio de Alqueva

SILVA, E.; BERBEL, J. An Azorean farms typology. New Medit - Mediterranean Journal of Economics, Agriculture and Environment 6:(1), p. 51-54, 2007.

SOLANO, C.; LEÓN, H.; PÉREZ, E.; HERRERO, M. Characterising objectives profiles of Costa Rican dairy farmers. Agricultural Systems 67: (1), p. 153-179, 2001.

SOLANO, C.; LEÓN, H.; PÉREZ, E.; HERRERO, M. The role of personal information sources on the decision-making process of Costa Rican dairy farmers. Agricultural Systems 76: (1), p. 3-18, 2003.

TRANTER, R.; COSTA, L.; KNAPP, T.; LITTLE, J.; SOTTOMAYOR, M. Asking Farmers about their Response to the Proposed Bond Scheme. In R.B. Tranter and A. Swinbank, Eds.), A Bond Scheme for Common Agricultural Policy Reform, Wallingford: CABI Publishing, p. 127-148, 2004.

USDA. Decoupled payments in a changing policy Setting, Washington D.C.: USDA, Agricultural Economic Report No. AER838, 2004.

VERHEES, F. J. H. M.; MEULENBERG, M. T. G.; PENINGS, J. M. E. The influence of market factors on intention to adopt a "radical" product innovation by farmers. Paper presented in American Agricultural Economics Meeting Providence, Rhode Island, 2005.

WILLOCK, J.; DEARY, I. J.; EDWARDS-JONES, G.; GIBSON, G.; MCGREGOR, M. J.; SUTHERLAND, A.; DENT, J. B.; MORGAN, O.; GRIEVE, R. The role of attitudes and objectivesin farmer decision making: Business and environmentally oriented behaviour in Scotland. Journal of Agricultural Economics, 50 (3), p. 286303, 1999a.

WILLOCK, J.; DEARY, I.; MCGREGOR, M.; SUTHERLAND, A.; EDWARDJONES, G.; MORGAN, O.; DENT, B.; GRIEVE, R.; GIBSON, G.; AUSTIN, E. Farmers' attitudes, objectives, behaviors, and personality traits: The Edinburgh study of decision making on farms. Journal of Vocational Behaviour 54 (1), p. 5-36, 1999b.

ZARAFSHANI, K.; ALIBAYGI, A. H.; NASRIN, A. N. 2008. The utility of discriminant analysis for predicting farmers' intentions to participate in farmermanaged irrigation systems in Iran. Journal of Applied Sciences 8 (4), p. 697-701, 2008. 